\title{
Winter regime of temperature and snow accumulation as a factor of ground freezing depth variations
}

\author{
Denis Frolov* \\ Lomonosov Moscow State University, Geographical Faculty, 1 Leninskie gory, 119991, Moscow, \\ Russia
}

\begin{abstract}
The observations of ground freezing depth in the conditions of bare soil and under natural cover have been carried out at the sites of meteorological observatory of Lomonosov Moscow State University since the observatory's foundation in 1954. For estimation of role of snow cover in variations of ground freezing depth the calculations of ground freezing depth were conducted using the meteorological data on air temperature and snow thickness for winter seasons of 2011/12-2018/19. The calculating scheme for ground freezing is constructed on the basis of three layer media heat conductivity problem (snow cover, frozen and thawed ground) with phase transition on the boundary of frozen and unfrozen ground. Heat balance equation includes phase transition energy, inflow of heat from unfrozen ground and outflow to frozen ground, snow cover and atmosphere. The heat flux is calculated on the basis of Fourier law as a product of heat conductivity and temperature gradient. It is supposed, that the temperature changes in each media linearly. The comparison of calculated and observed values of ground freezing indicates good correspondence.
\end{abstract}

\section{Introduction}

Snow cover and frozen ground are essential elements for cryosphere and hydrology of Earth climate system [1,2]. They are also one of the key factors of climate change. The climatic factors, such as temperature conditions and snow cover thickness by-its-turn undergo a change and variations. Variations of climatic conditions, snow cover thickness and coupled with it ground freezing depth may also lead to permafrost thawing and the damage of constructions and pipelines, the landslides on the slopes. In particular in relation to recent decade's climate alteration at least in the Arctic, the growth of ground temperature and increase of seasonal thawed layer cannot be explained only by the growth of airtemperature. The alteration of snow cover thickness also brings considerable impact. Summary effect from alteration of air-temperature and snow cover thickness can result in additional few degrees heating $\left(+2+3^{\circ} \mathrm{C}\right)$. It is not critical for permanently frozen ground with the temperature of $-8-10^{\circ} \mathrm{C}$, but for the permanently frozen ground with the

\footnotetext{
* Corresponding author: denisfrolovm@mail.ru
} 
temperature of $-3-5^{\circ} \mathrm{C}$ and higher this may lead to thawing and increase of seasonal active layer. Moreover the monitoring and thermal state measurements of frozen ground are rather simple, but the calculations and modelling of these processes is rather a sophisticated issue. For assessment of influence of air-temperature and snow cover thickness variations on the dynamics of the ground freezing and thawing depth, the number of models and calculating schemes were developed. For example, V.A. Kudriavcev [3] characterized warming and cooling action of snow cover on the ground depending on snow accumulation regime and on its duration and suggested the equation for estimation of ground freezing depth including snow cover thickness, its thermal properties and amplitude of yearly air temperature oscillations. In the studies of A.V. Pavlov [4] snow cover on the ground surface is considered as additional layer with thermal resistance and this is used in the formula for ground freeing depth calculations.

\section{Material and methods}

In our study calculating scheme for estimation of ground freezing depth in the conditions of bare soil and covered with the snow ground surface is constructed as in [5-7]. We use the data on air temperature and snow cover thickness in the calculations. The example of calculations is performed for the site of the meteorological observatory of Lomonosov Moscow State University for winter seasons of 2011/12-2017/18 [8, 9].

The calculating scheme for ground freezing is constructed on basis of three layer media heat conductivity problem (snow cover, frozen and thawed ground) with phase transition on the boundary of frozen and unfrozen ground. Heat balance equation includes phase transition energy, inflow of heat from unfrozen ground and outflow to frozen ground, snow cover and atmosphere. The heat flux is calculated on basis of Fourier law as a product of heat conductivity and temperature gradient. It is supposed, that the temperature changes in each media linearly like in [10].

The calculations of freezing of bare and covered with snow ground in winter period on the basis of daily data on air temperature, snow thickness and heat conductivity of snow cover allows estimating the rate of movement of ground freezing interface during a winter period. The rate of movement of ground freezing interface can be expressed with the formulas:

$$
F_{1}=c L V+F_{2},
$$

or

$$
d h_{f g} / d \tau=V=\left(F_{1}-F_{2}\right) / c L,
$$

$F_{1}$ - is heat outflow through frozen ground (and snow cover) from ground freezing interface $\left(\mathrm{W} / \mathrm{m}^{2}\right)$ into atmosphere;

$c L V=c L d h_{f g} / d \tau$ - heat value for phase transition in the ground, $c$ - ground moisture content $\left(1-4 \mathrm{~kg} / \mathrm{cm}^{*} \mathrm{~m}^{2}\right.$ ), (last value correspond to full filling of porous by water for light clay with density $2000 \mathrm{~kg} / \mathrm{m}^{3}$ and porosity coefficient 0.617 [11])

$L$ - energy of $\mathrm{H}_{2} \mathrm{O}$ phase transition $(335 \mathrm{~kJ} / \mathrm{kg}), V$ - rate of movement of ground freezing interface $(\mathrm{cm} / \mathrm{s})$;

$F_{2}$ - heat outflow for cooling of thawed ground in front of ground freezing interface $\left(\mathrm{W} / \mathrm{m}^{2}\right)$.

Heat flux is expressed according to Fourier law by means of temperature gradient and heat conductivity as $F=-\lambda(\operatorname{grad} T)$. Heat conductivity and heat flux through combination of two media (snow and frozen ground) according to [12] can be expressed as: 


$$
F_{1}=-\lambda \frac{\Delta T}{\Delta x}=-\frac{\Delta T}{\left(\frac{\Delta x_{s}}{\lambda_{s}}+\frac{\Delta x_{f g}}{\lambda_{f g}}\right)}=\frac{-T_{\text {air }}}{\left(\frac{h_{s}}{\lambda_{s}}+\frac{h_{f g}}{\lambda_{f g}}\right)}
$$

Here $T_{\text {air }}$ - air temperature, $h_{s}$ and $h_{f g}$ - snow cover thickness and ground freezing depth, $\lambda_{s}$ and $\lambda_{f g}-$ heat conductivity of snow and frozen ground. This expression is valid also for $h_{s}$ $=0$.

It was supposed, that on the depth of $10 \mathrm{~m}$ in ground there is a point of zero annual temperature oscillation with temperature value $T_{0}=7^{\circ} \mathrm{C}$. That is why

$$
F_{2}=-\lambda_{\text {thg }} \frac{\Delta T}{\Delta x}=\lambda_{\text {thg }} \frac{T_{0}}{10-h_{f g}}
$$

Here $\lambda_{\text {thg }}$ - heat conductivity of thawed ground. According to [11] averaged heat conductivity of the thawed and frozen ground $\lambda_{\text {thg }}$ and $\lambda_{f g}$ was assumed to be equal 1.4 and $1.8 \mathrm{~W} / \mathrm{m}{ }^{\circ} \mathrm{C}$ correspondingly.

The differential scheme $h_{\mathrm{fg}}\left(t_{\mathrm{n}+1}\right)=h_{\mathrm{fg}}\left(t_{\mathrm{n}}\right)+\Delta t \quad V\left(t_{\mathrm{n}}\right)$ was constructed by Euler approximation for the equation for the rate of ground freezing depth.

By elaborated differential scheme the calculations of ground freezing depth were carried out for the winter seasons of 2011/12-2017/18. The calculations were performed with the time step of one day. For initial conditions, it was supposed that frozen ground thickness $h_{f g}$ was equal $0.5 \mathrm{~cm}$. For each time step (each day) the rate of movement of freezing interface $V$ and the value frozen ground thickness $h_{f g}$ for the next day (time-step) were calculated.

\section{Results and discussion}

Considered in this work, the method of linear gradients differs from other ones, presented for example in the classical book of A.N. Tikhonov and A.A. Samarskii [13] (first edition from 1951) or in the works of A.V. Pavlov [4], where the heat conductivity partial differential equation of second order for space and first order for time is used for calculation of seasonal dynamics of ground freezing depth. In this work there is only reduced ordinary differential equation (ODE) of first order for time is used. Solving of this reduced first order ODE is simpler and could be done within Excel program.

The results of calculations of maximum ground freezing depth for the bare site surface for the winter seasons of 2011/12-2017/18 and theirs comparison with the observed data are displayed on the Fig. 1 and indicate general consistency.

The example of results of calculations for ground freezing depth for the bare and covered with snow site surface for the winter seasons 2017/18 and theirs comparison with the observed data is displayed on the Fig. 2. 


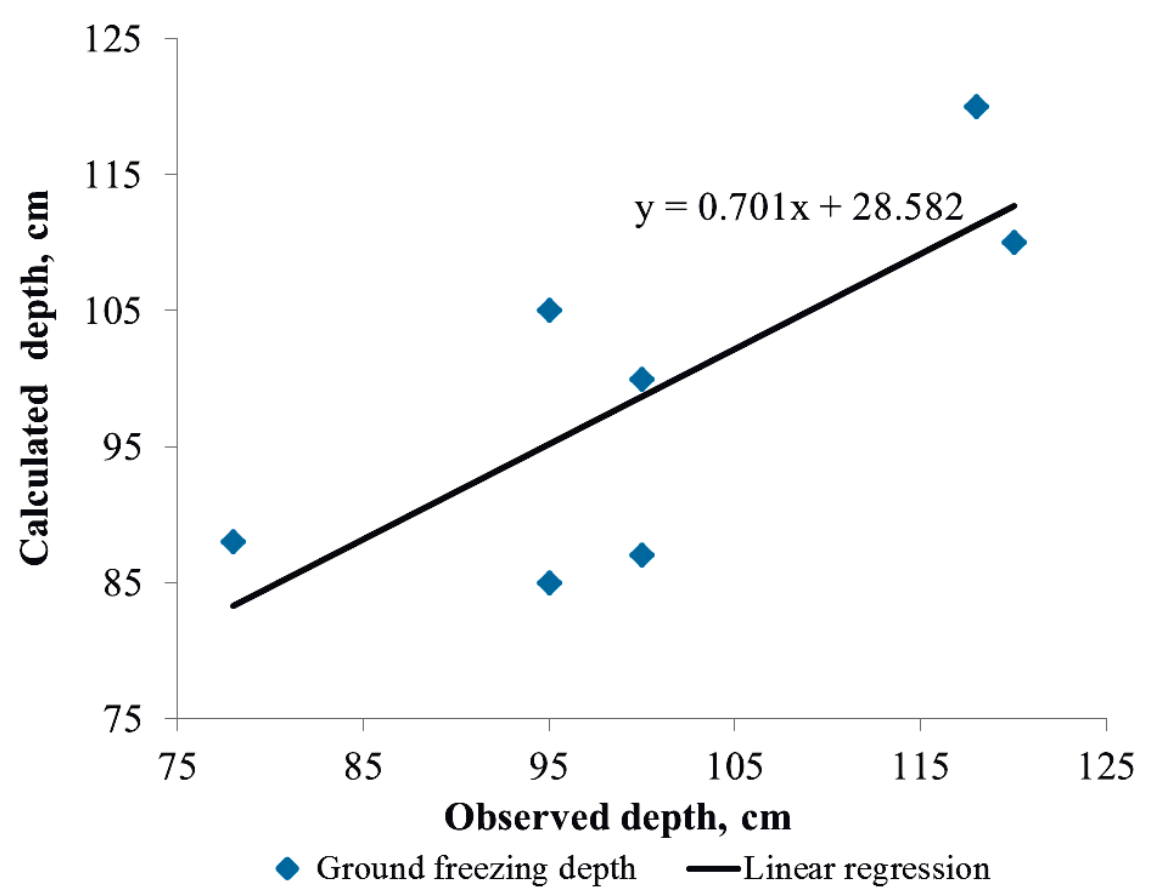

Fig. 1. Maximal ground freezing depth for the bare site surface of the meteorological observatory of Lomonosov Moscow State University for the winter seasons of 2011/12-2017/18 and theirs comparison with the observed data.

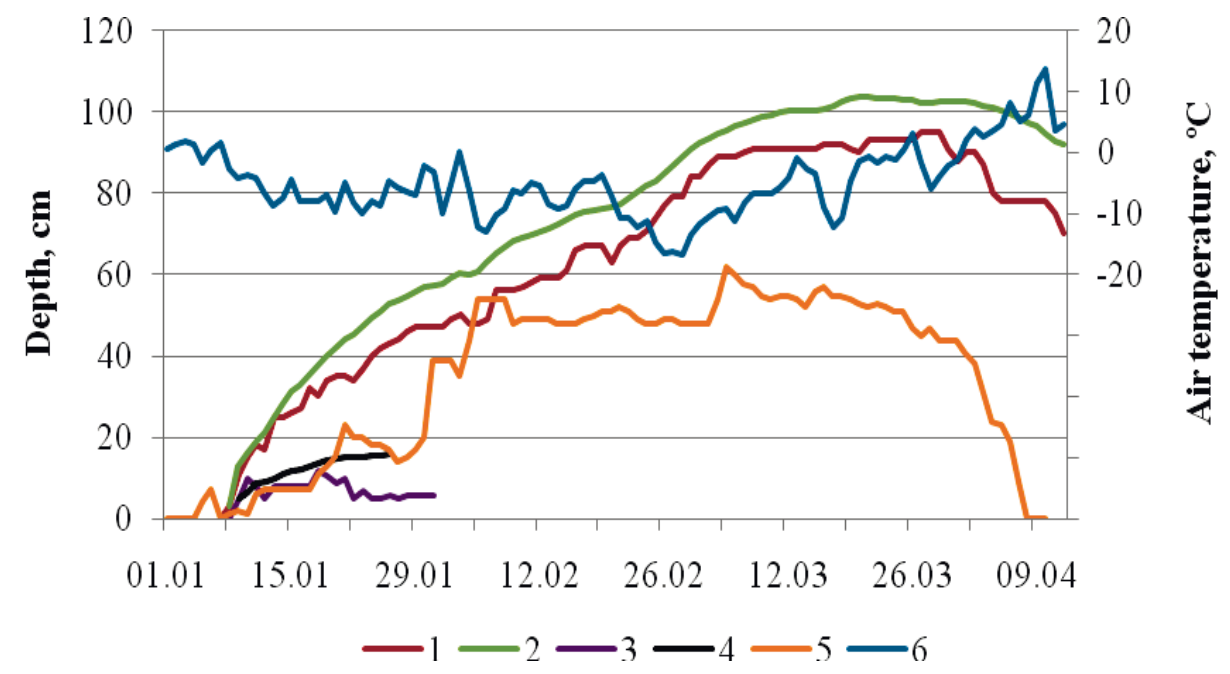

Fig. 2. The results of calculations for ground freezing depth for the bare (2) and covered with snow site surface (4) of the meteorological observatory of Lomonosov Moscow State University for the winter seasons 2017/18 and theirs comparison with the observed data (1 and 3). Air temperature (6) and snow cover thickness (5).

The study is carried out in a frame of state topic «Mapping, modelling and assessment of risk of hazardous natural processes» AAAA-A16-116032810093-2. 


\section{References}

1. E.E. Jafarov, E.T. Coon, D.R. Harp, C.J. Wilson, S.L. Painter, A.L. Atchley, V.E. Romanovsky Modeling the role of preferential snow accumulation in through talik development and hillslope groundwater flow in a transitional permafrost landscape, Environmental Research Letters, 13, 105006 (2018)

2. J. Qi, L. Wang, J. Zhou, L. Song, X. Li, T. Zeng, JGR: Atmospheres, 124, 23, 12985 13004 (2019)

3. V.A. Kudryavtsev Temperature of the Upper Horizons of Permafrost Thickness within the USSR. Akad. Nauk SSSR, Leningrad (1954) (in Russian)

4. A.V. Pavlov Cryolithozone monitoring. Academician publishing house, Novosibirsk (2008) (in Russian)

5. D.M. Frolov Calculating scheme of ground freezing depth on the basis of data on seasonal snowfall deposition, snow cower accumulation and temperature variation // IOP Conference Series: Earth and Environmental Science, 386, 1-7. (2019)

6. D.M. Frolov Influence of Intra-seasonal Snowfall Deposition, the Peculiarities of Snow Cover Accumulation and Winter Season Temperature Variation on Ground Freezing Depth. In: Petriaev A., Konon A. (eds) Transportation Soil Engineering in Cold Regions, Volume 1. Lecture Notes in Civil Engineering, 49. 3-8. Springer, Singapore. (2020)

7. V.N. Golubev, M.N. Petrushina, D.M. Frolov, Winter regime of temperature and precipitation as a factor of snow-cover distribution and its stratigraphy. Annals of Glaciology 49, 179-186 (2008).

8. Environmental and climate characteristics of the atmosphere in 2011-2016 according to the measurements of the Meteorological Observatory of Moscow State University Moscow, MAKS Press (2012-2017) (in Russian)

9. Environmental and climate characteristics of the atmosphere in Moscow in 2017-2018 according to the measurements of the Moscow State University Meteorological Observatory. Ed. by M.A.Lokoshchenko, Moscow, MAKS Press (2018-2019) (in Russian)

10. A.T. DeGaetano, M.D. Cameron, and D.S. Wilks, JAM, 40 (3), 546-555 (2001)

11. V.T. Trofimov, Soil science. MSU Publishing, Moscow (2005) (in Russian)

12. M.A. Mikheev, I.M. Mikheeva, Fundamentals of heat transfer. Energiya, Moscow (1977) (in Russian)

13. A.N. Tikhonov, A.A. Samarskii, Equations of Mathematical Physics. Dover Publications Inc., New York (1990) 